\title{
Effect of Inspiratory Muscle Training with Elastic Taping on Forced vital capacity and Sway Area in Stroke Patients
}

\author{
Shin Jun Park \\ Department of Physical Therapy, Gangdong University, Eumseong, Korea
}

Purpose: The purpose of this study was to evaluate the forced vital capacity and sway area of respiratory muscles taping with threshold inspiratory muscles training for 1 week.

Methods: Nineteen stroke patients were divided into two groups: experimental group (respiratory muscles taping with threshold inspiratory muscles training, $n=10$ ) and control group (threshold inspiratory muscles training, $n=9$ ). Forced vital capacity tests were performed using a spirometer. The instrument records the forced vital capacity (FVC). COP excursion test was performed using Zebris. The instrument records the sway area. All tests were measured before and after intervention.

Results: The experimental group and control group showed significant increase in FVC $(p<0.05)$. The sway area showed a significant decrease only in the experimental group $(p<0.05)$. The FVC and sway area was no significant difference between the two groups $(p>0.05)$. Conclusion: Threshold inspiratory muscles training is an effective intervention for improving FVC. Threshold inspiratory muscles training with respiratory taping is an effective intervention for improving FVC and sway area. Threshold inspiratory muscles training with respiratory taping can improve balance ability.

Keywords: Inspiratory muscle training, Taping, Stroke

\section{INTRODUCTION}

Brain attack or stroke patients have decreased paretic side diaphragmatic movement and pulmonary function. ${ }^{1}$ The paretic respiratory muscle tone of stroke patients is reduced compared to the non-paretic side muscle tone ${ }^{2}$ and muscle weakness of this hemi side represents balance impairment. ${ }^{3}$ Inspiratory muscle training has been used for stroke respiratory rehabilitation because non-community dwelling stroke survivors show weaker inspiratory muscles than expiratory muscles. ${ }^{4-6}$ Inspiratory muscle training can improve dynamic balance ability. ${ }^{7}$

Recently taping methods have been introduced in the respiratory rehabilitation of stroke patients. ${ }^{2}$ Taping is a noninvasive, safe method that has been introduced as an upper arm or trunk intervention for stroke patients because of facilitation and relaxation depending on the attachment method. ${ }^{8}$ When applied in combination with

Received Mar 18, 2020 Revised Apr 7, 2020

Accepted Apr 13, 2020

Corresponding author Shin Jun Park

E-mail 3178310@naver.com other intervention methods, there is an advantage that it can be performed at the same time without disturbing the movement.

Joint mobilization with respiratory taping in stroke patients showed better forced vital capacity than single methods. ${ }^{9}$ Diaphragmatic breathing exercise with taping showed increased inspiratory muscle tone and decreased $\mathrm{SpO} 2{ }^{2}$

In previous studies, however, no studies have examined pulmonary function and sway area after taping intervention with threshold inspiratory muscle training (IMT). Threshold IMT is a device that can set the intensity according to the individual patient through the threshold valve and can increase and decrease according to the physical condition that the patient feels. Several studies have demonstrated that this device is a method that increases the pulmonary function and respiratory pressure of stroke patients. ${ }^{5,6,10}$ The ventilatory function of stroke patients is related to the balance ability ${ }^{11}$ and the threshold IMT can improve inspiratory and expiratory muscle activity and

Copylight (C)2020 The Korean Society of Physical Therapy

This is an Open Access article distribute under the terms of the Creative Commons Attribution Non-commercial License (https:// creativecommons.org/license/by-nc/4.o.) which permits unrestricted non-commercial use, distribution, and reproduction in any medium, provided the original work is properly cited. 
forced vital capacity. ${ }^{5}$ In addition, trunk correction taping and scapular setting exercises have been shown to improve the sitting balance of stroke patients. ${ }^{12}$ In addition, inspiratory muscle training can promote proprioception for postural control of the trunk..$^{13}$ Therefore, it is necessary to confirm whether threshold IMT with taping affects the standing balance ability. The purpose of this study was to evaluate the effect of simultaneous threshold IMT and respiratory taping on the sway area and forced vital capacity in stroke patients.

\section{METHODS}

\section{Subjects}

This study was conducted on 20 stroke patients in A rehabilitation hospital in Gyeonggi do. All subjects were those who had been diagnosed with stroke for more than 6 months, and had no specific respiratory complications, orthopedic disorders in the chest, or no skin disease. Also, subjects were able to communicate independently (K-MMSE 24 points or more) with standing posture for 30 seconds.

After the initial evaluation, 20 subjects were divided into experimental group (threshold IMT with respiratory taping, $\mathrm{n}=10$ ) and control group (only threshold IMT, $\mathrm{n}=10$ ). However, one patient was excluded due to discharge from the control group during the study, so the total of 19 subjects were statistically analyzed in $10 \mathrm{ex}-$ perimental group and 9 control group (Table 1).

\section{Measurement methods}

All evaluations were conducted by the researcher and one assistant who was in the fifth year or longer.

\section{1) forced vital capacity measurement}

Forced vital capacity tests were performed using a spirometer (Mi-

Table 1. General characteristics

\begin{tabular}{lccc}
\hline & $\begin{array}{c}\text { Experimental } \\
\text { group }(n=10)\end{array}$ & $\begin{array}{c}\text { Control } \\
\text { group }(n=9)\end{array}$ & $p$ \\
\hline Gender (male/female) & $8 / 2$ & $6 / 3$ & 0.510 \\
Affected side (left/right) & $4 / 6$ & $4 / 5$ & 0.845 \\
Onset (month) & $13.00 \pm 2.67$ & $13.56 \pm 2.83$ & 0.773 \\
K-MMSE (point) & $25.50 \pm 1.35$ & $26.56 \pm 1.81$ & 0.183 \\
Age (yr) & $66.40 \pm 4.48$ & $64.44 \pm 6.95$ & 0.566 \\
Height (cm) & $166.00 \pm 5.79$ & $167.33 \pm 7.02$ & 0.593 \\
Weight (kg) & $67.90 \pm 6.94$ & $67.67 \pm 6.10$ & 0.967 \\
\hline
\end{tabular}

K-MMSE: Korean version of Mini Mental State Examination.
croLab spirometer ML3500 MK6, UK). The instrument records the forced vital capacity (FVC) on the instrument's LCD panel when the measurement is performed. The FVC estimates the airflow by inhaling the air to the maximum and then exhaling. The subject was ready to take measurements in a sitting position. Before the measurements, the evaluator showed a demonstration, detailing how to breathe the mouthpiece as much as possible, and how to exhale as much as possible for 6 seconds. The evaluator encouraged the use of as much air as possible and the pouring of air for 6 seconds, and used the highest of the three measurements

\section{2) Standing balance measurement}

Standing balance test was performed using Zebris (FDM-S, Medical $\mathrm{GmbH}$, Germany). The instrument records the sway area, path length, and average velocity in the personal notebook when the measurement is performed. The sway area test assessed the area of the center of pressure moving in a straight posture for 30 seconds on the force plate. ${ }^{14}$ The subject placed the foot naturally on the force plate and observed the marking point of $5 \mathrm{~cm}^{2}$ on the front $3 \mathrm{~m}$.

\section{Intervention Methods}

The intervention period was 1 day, 5 days a week, 1 hour (30 minutes in the morning and 30 minutes in the afternoon). Since taping is the most effective period 24 hours after attachment, taping was changed once a day. ${ }^{15}$ All subjects were subjects receiving neuro-development treatment, gait and mat exercise, and occupational therapy.

\section{1) Threshold inspiratory muscle training}

All subjects in this study performed Threshold IMT (Philips Respironics, USA) in the room and space besides the treatment schedule. Maximal inspiratory pressure (MIP) was measured by MicroRPM (Care Fusion, UK) for initial intensity setting. The intensity was 30\% of the MIP of each subject. When the RPE was less than 13, the pressure was increased by $2 \mathrm{cmH}_{2} \mathrm{O}$, between 13 and 15 was increased by $1 \mathrm{cmH}_{2} \mathrm{O}$, while when the pressure was increased by 15 , the resistance was decreased by $2 \mathrm{cmH}_{2} \mathrm{O} .{ }^{16}$ Training was performed in 3 sets of 15 repetitions. The researchers trained each participant and guardian with training guidelines and methods until proper training performance was achieved, and observed the training performance by supervising and supervising daily for one week. 


\section{2) Respiratory taping methods}

The respiratory muscle taping methods used a $5 \mathrm{~cm}$ wide elastic tape (Benefact, Nippon Sigmax Co., ltd, Japan). The tape used in this study consisted of four I-tape. First, two I tapes were used. The researcher attached one end of the tape to the subject's cervical 7 th cervical spinous process, then wrapped the tape under the ribs and attached the other end near the xiphoid process (Figure 1). The other side was similarly attached. The remaining two I - tapes were attached to each other in the transverse direction above the scapular bone (Figure 2). Tensile strength of the tape was 75\%. The method of applying $75 \%$ of elongation was to make an I-shaped tape according to the body length of the subject, fold the manufactured tape into quadruplicate, remove one-half of the tape, and attach the tension by applying the tension. ${ }^{17}$ After taping, it was instructed to remove it if it feels discomfort by itching or skin pulling. In this study, the study group received a threshold IMT after attaching the respiratory muscle taping.

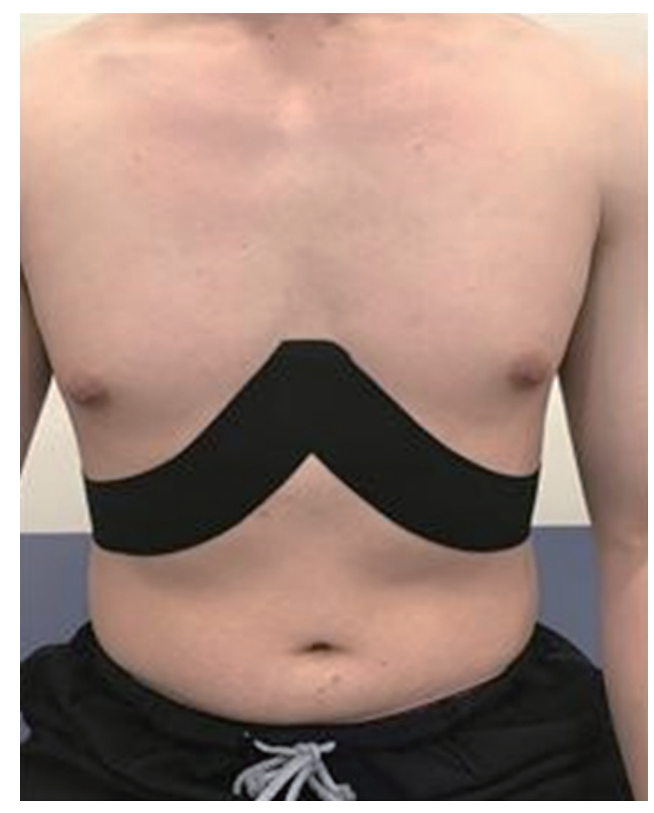

Figure 1. The taping methods anterior view.

\section{Statistical analysis}

Data analysis of this study was statistically treated with SPSS 20.0. The general characteristics of the subjects, the sway area, and the pulmonary function were calculated using descriptive statistics. The difference in FVC and sway area before and after the intervention was analyzed by Wilcoxon's signed-ranks test, and the difference between the study groups was Mann-Whitney U test Respectively. All statistical analyzes were performed at set $\alpha=0.05$.

\section{RESULTS}

\section{Changes in pulmonary function, sway area before and after intervention}

The results of the study are shown in Table 2. Before intervention, there was no significant difference in FVC and sway area between the two groups. There was a significant increase in FVC, in experimental group and control group after 1 week of intervention $(\mathrm{p}<0.05)$. In addition, the sway area showed a significant decrease

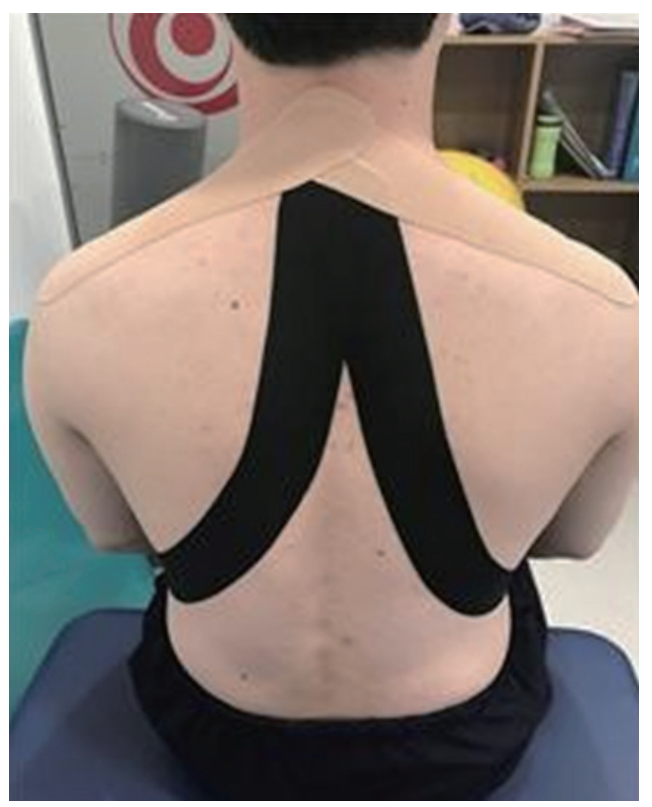

Figure 2. The taping methods posterior view.

Table 2. Comparison of forced vital capacity, sway area within and between group

\begin{tabular}{|c|c|c|c|c|}
\hline \multirow{2}{*}{ Classification } & \multicolumn{2}{|c|}{ Experimental group $(n=10)$} & \multicolumn{2}{|c|}{ Control group $(n=9)$} \\
\hline & Before & After & Before & After \\
\hline $\mathrm{FVC}(\mathrm{L})$ & $2.79 \pm 0.47$ & $3.03 \pm 0.56 *$ & $2.87 \pm 0.78$ & $3.33 \pm 0.64 *$ \\
\hline Sway area $\left(\mathrm{mm}^{2} / \mathrm{mm}\right)$ & $136.90 \pm 37.82$ & $84.33 \pm 34.59 *$ & $137.26 \pm 31.67$ & $107.98 \pm 42.31$ \\
\hline
\end{tabular}


in the experimental group $(\mathrm{p}<0.05)$, however there was no significant difference in the control group $(\mathrm{p}>0.05)$. There was no significant difference between the two groups ( $\mathrm{p}>0.05)$.

\section{DISCUSSION}

The purpose of this study was to investigate the effect of threshold IMT with respiratory taping on forced vital capacity (FVC) and sway area in patients with stroke after a week. There was a significant increase in FVC in both experimental group and control group. However, there was no significant difference in FVC between the two groups. Diaphragmatic exercises and respiratory tapings showed significant differences in respiratory muscle tone and SpO2 reduction in stroke patients, and no difference in single diaphragmatic exercises. ${ }^{2}$ The reason for the difference between the results of this study and the results of the intervention period seems to be the difference. The diaphragmatic exercise and taping in previous studies compared immediate effects after taping, so it is rather difficult to compare it with the total of ten times of training five times a week, twice a day.

Reported that there were no differences between single threshold IMT in FVC, FEV1, and PEF as a result of applying threshold IMT and taping 12 times a week for 4 weeks to healthy subjects. ${ }^{18} \mathrm{FVC}$, FEV1, and PEF are the results obtained by measuring the air flow rate after exhaling with maximum force after the maximum inhalation. Single threshold IMT can increase FVC, FEV1, and PEF of stroke patients. ${ }^{5}$ Therefore, we suggest that the single threshold IMT results in a ceiling effect that is sufficient to enhance the pulmonary function of stroke patients.

Intensive exercise for 5 hours per week for 2 week and 1 hour for stroke was significantly increased in the patients with stroke, FEV1, $10 \mathrm{~m}$ walking and 6 minutes walking compared to the control group. ${ }^{19}$ This study was carried out one week earlier than the period of the previous study, and there was a significant clinical significance since both of the groups that performed the hold IMT showed a significant increase in pulmonary function.

In the present study, the experimental group showed a significant decrease in the sway area, but there was no significant difference in the control group.

The threshold IMT and therapeutic exercise showed a significant increase in the berg balance scale of the stroke patients, but there was also a significant increase in the control group of single therapeutic exercise, and there was no significant difference between the two groups.$^{20}$ Previous researchers concluded that it is difficult to increase the balance ability with threshold IMT. ${ }^{20}$ The 6 week threshold IMT increased the balance ability associated with the upper extremity, but not the lower extremity balance ability, thus supporting the findings that the threshold IMT alone could not reduce the sway area?

The kinesiotaping attached to the trunk increases the sitting balance by correcting trunk alignment and improving trunk stability. ${ }^{21}$ Increased sitting posture stability is correlated with standing posture stability. ${ }^{22}$ The taping attached in this study is a method of attaching for the purpose of assisting the diaphragm contraction. The diaphragm contraction not only improves inspiration, but also increases abdominal pressure, thereby increasing the stability of the torso. ${ }^{23}$ Therefore, it seems that the sway area was increased in the study group with taping.

However, there was a significant decrease in the sway area in the experimental group with taping. single threshold IMT could not show improvement in minute ventilation, but threshold IMT with taping could increase minute ventilation. ${ }^{18}$ Minute ventilation is the rate of breathing, and trunk control increases as minute ventilation increases. ${ }^{11}$ Trunk correction taping and scapular setting exercises are more effective for trunk control and trunk muscle activity in stroke patients than for single scapular setting exercises. ${ }^{12}$ Previous researchers found that sensory input via taping increased the trunk muscle activity of stroke patients and improved trunk control ability. Therefore, respiratory muscle taping seems to have reduced the sway area by increasing the trunk muscle activity ${ }^{16}$ and ventilation function ${ }^{18}$ required for balance control.

These results suggest that the threshold IMT can increase the pulmonary function of the stroke patients, and if taping is applied at the same time, it is possible to reduce the sway area, which means standing balance. However, the one-week intervention period in this study did not confirm the long-term effects of the intervention, and it did not identify the variables for how long the effect lasted when taping was removed. In addition, there is opposition study that health people do not have effect on single application of respiratory muscle taping. ${ }^{20}$ Therefore, in future studies, it would be necessary to confirm the effect of removing taping on the respiratory muscle of stroke patients and the difference in the single application. 


\section{REFERENCES}

1. Jung KJ, Park JY, Hwang DW et al. Ultrasonographic diaphragmatic motion analysis and its correlation with pulmonary function in hemiplegic stroke patients. Ann Rehabil Med. 2014;38(1):29-37.

2. Wang JS, Cho KH, Park SJ. The immediate effect of diaphragm taping with breathing exercise on muscle tone and stiffness of respiratory muscles and SpO2 in stroke patient. J Phys Ther Sci. 2017;29(6):970-3.

3. Tyson SF, Hanley M, Chillala J et al. Balance disability after stroke. Phys Ther. 2006;86(1):30-8.

4. Pinheiro MB, Polese JC, Faria CD et al. Inspiratory muscular weakness is most evident in chronic stroke survivors with lower walking speeds. Eur J Phys Rehabil Med. 2014;50(3):301-7.

5. Park SJ. The effects of rib cage joint mobilization and threshold inspiratory muscle training applying respiratory function and respiratory activation of stroke patients. The graduate school of yong-in university, Master Thesis. 2016.

6. Britto RR, Rezende NR, Marinho KC et al. Inspiratory muscular training in chronic stroke survivors: a randomized controlled trial. Arch Phys Med Rehabil. 2011;92(2):184-90.

7. Choi EJ, Chun JH, Hong JG. Effects of a 6-weeks inspiratory training on upper and lower quarter dynamic balance, and inspiratory muscle strength. The Korean journal of physical education. 2017;56(2):339-47.

8. Jaraczewska E, Long C. Kinesio taping in stroke: improving functional use of the upper extremity in hemiplegia. Top Stroke Rehabil. 2006; 13(3):31-42.

9. Park SJ, Kim SH, Min KO. Effects of Joint Mobilization and Respiratory Muscle Taping on Pulmonary Function and Chest Expansion Ability in Patients with Chronic Stroke. IAPTR. 2017;8(3):1229-34.

10. Xiao Y, Luo M, Wang J et al. Inspiratory muscle training for the recovery of function after stroke. Cochrane Database Syst Rev. 2012;(5):1-19.

11. Fayed IH, Badawy MS, Mansour WT et al. Comparative Study of Ventilatory Function in Relation to Trunk Control between Acute and Chronic Stroke Patients. Group. 2015;50(8.76):41-57.

12. Park SJ, Jo KH. The effects trunk correction taping on trunk muscle ac- tivity and stability, upper extremity function in stroke patients. J Digit Converg. 2017;15(2):411-9.

13. Janssens L1, McConnell AK, Pijnenburg M et al. Inspiratory muscle training affects proprioceptive use and low back pain. Med Sci Sports Exerc. 2015;47(1):12-9.

14. Pau M, Mandaresu S, Leban B et al. Short-term effects of backpack carriage on plantar pressure and gait in schoolchildren. J Electromyogr Kinesiol. 2015;25(2):406-12.

15. Jung SR, Lee SU, Choi HY. The Effects of Inspiratory Kinesio Taping for Achievement of Respiratory Activity and Pulmonary Function. Journal of sport and Leisure Studies. 2012;48(2):849-57.

16. Fry DK, Pfalzer LA, Chokshi AR et al. Randomized control trial of effects of a 10-week inspiratory muscle training program on measures of pulmonary function in persons with multiple sclerosis. J Neurol Phys Ther. 2007;31(4):162-72.

17. Langendoen J, Sertel K. Kinesiology Taping. Robert Rose Inc, 2014;1367.

18. Lee MS, Kim MC, Ahn CJ. Impact of Concurrent Inspiratory Muscle Training and Tape on Inspiratory Muscle Strength, Endurance and Pulmonary Function. Journal of The Korean Society of Integrative Medicine. 2014;2(3):65-73.

19. Choi CS, Oh DW. The effects of intensive chest mobility exercise on increasing pulmonary function and gait in stroke patients. Inst Spec Educ Rehabitation Sci. 2012;51(2):221-39.

20. Zübeyir S, Nilüfer K, Burcu C et al. The effect of kinesiology taping on respiratory muscle strength. J Phys Ther Sci. 2012;24(3):241-4.

21. Şimşşek TT, Türkücüoğğlu B, Çokal N et al. The effects of kinesio taping on sitting posture,functional independence and gross motor function in children with cerebral palsy. Disabil Rehabil. 2011;33(2122):2058-63.

22. Helmy H, Emara T, Mously SE et al. Impact of trunk control on balance and functional abilities in chronic stroke patients. Egypt J Neurol Psychiat Neurosurg. 2014;51(3):327-31.

23. Akuthota V, Ferreiro A, Moore T et al. Core stability exercise principles. Current sports medicine reports. 2008;7(1):39-44. 